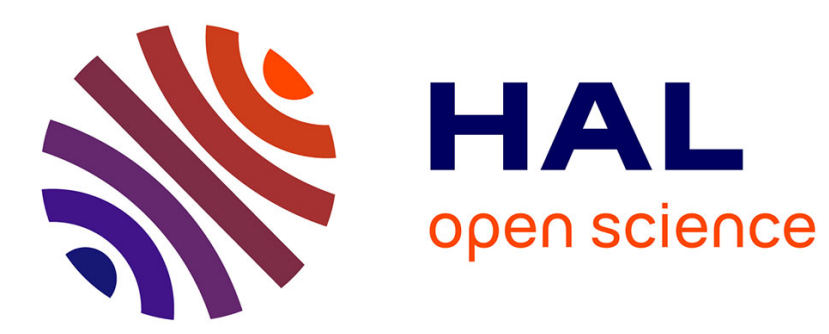

\title{
Measurement of Lipid Transport in Mitochondria by the MTL Complex
}

\author{
Juliette Jouhet, Valérie Gros, Morgane Michaud
}

\section{To cite this version:}

Juliette Jouhet, Valérie Gros, Morgane Michaud. Measurement of Lipid Transport in Mitochondria by the MTL Complex. Intracellular lipid transport. Series: Methods in Molecular Biology, Springer, pp.69-93, 2019. hal-02151145

\section{HAL Id: hal-02151145 \\ https://hal.science/hal-02151145}

Submitted on 22 Oct 2020

HAL is a multi-disciplinary open access archive for the deposit and dissemination of scientific research documents, whether they are published or not. The documents may come from teaching and research institutions in France or abroad, or from public or private research centers.
L'archive ouverte pluridisciplinaire HAL, est destinée au dépôt et à la diffusion de documents scientifiques de niveau recherche, publiés ou non, émanant des établissements d'enseignement et de recherche français ou étrangers, des laboratoires publics ou privés. 


\title{
Chapter 7
}

\section{Measurement of lipid transport in mitochondria by the MTL complex}

\author{
J. Jouhet, V. Gros, M. Michaud
}

\begin{abstract}
Membrane biogenesis requires an extensive traffic of lipids between different cell compartments. Two main pathways, the vesicular and non-vesicular pathways, are involved in such process. Whereas the mechanisms involved in the vesicular trafficking are well understood, fewer is known about nonvesicular lipid trafficking, particularly in plants. This pathway involves the direct exchange of lipids at contact sites (MCSs) between organelles. In plants, an extensive traffic of the chloroplast-synthesized digalactosyldiacylglycerol (DGDG) to mitochondria occurs during phosphate starvation. This lipid exchange occurs by non-vesicular trafficking pathways at MCSs between mitochondria and plastids. By a biochemical approach, a mitochondrial lipoproteic super-complex called MTL (Mitochondrial Transmembrane Lipoprotein complex) involved in mitochondria lipid trafficking has been identified in Arabidopsis thaliana. This protocol describes the method to isolate the MTL complex and to study the implication of a component of this complex (AtMic60) in mitochondria lipid trafficking.
\end{abstract}

Key words: mitochondria, lipid transfer, MTL complex, CN-PAGE, mass spectrometry.

\section{Introduction}

Eukaryotic cells are composed of different organelles that allow the compartmentalization of cellular functions. Each organelle is delineated by at least one membrane composed of a specific assembly of lipids and proteins. This specific composition defines the identity of each organelle and is required to ensure their proper functions. Lipids play multiple roles in the regulation of the architecture and the function of membranes. They are synthesized in different cell compartments and have to be properly distributed to other organelles. Two main lipid trafficking pathways have been described: the vesicular and the non-vesicular pathways. The vesicular pathway is involved in lipid and protein trafficking to the endomembrane system and has been well studied in different organisms [1,2]. The non-vesicular pathway involves the exchange of lipids directly between two membranes, usually at contact sites (MCSs), when membranes are at a distance $\leq 30 \mathrm{~nm}$ [3]. This pathway requires the establishment of MCSs, by the so-called tethering proteins or complexes, followed by the transfer of the lipid from one membrane to another.

Identification of proteins involved in non-vesicular lipid trafficking in cells is limited mainly by technical issues. In vivo strategies to investigate the role of a protein on lipid trafficking are mostly based 1) on the analysis of the steady state level of lipids in cells or organelles in a mutant or 2) on experiments based on lipid labelling. However, the steady state of a lipid relies on several metabolic processes besides trafficking, such as synthesis, degradation or modification. Lipid labelling experiments can be limited by the availability of labelled (fluorescent, radioactive...) substrates that can be easily uptake by cells and behave like endogenous lipids. In addition, because of the presence of several redundant pathways, the effect of a protein on lipid trafficking can be masked in a mutant. Several in vitro assays using liposomes and purified proteins have also been developed to study the ability of a protein to transfer 
lipids $[4,5]$. However, these assays are adapted for soluble proteins and some specific factors, such as lipid composition of the donor and acceptor liposomes or the presence of partners, might be required to detect and measure the transfer activity of a protein by such assays.

Recently, we took advantage of the massive lipid remodeling triggered by phosphate starvation to identify proteins involved in lipid trafficking to mitochondria in Arabidopsis thaliana [6-8]. During phosphate starvation, the phospholipids present in mitochondria membranes are partially degraded to release phosphate [6]. To maintain the integrity of mitochondria membranes, a massive transfer of the non-phosphorous galactoglycerolipid digalactosyldiacylglycerol (DGDG) occurs from chloroplast to mitochondria [6]. DGDG is synthesized in plastids and is mainly retained in this compartment in normal growth condition [9]. During Pi starvation the level of DGDG in mitochondria drastically increase from 2 to $20 \%[6,8]$. This transfer occurs at MCSs between chloroplasts and mitochondria, which number increases during Pi starvation [6]. Thus this particular situation constitutes a powerful tool to study lipid trafficking to mitochondria as we can 1) turn on/off the traffic of DGDG to mitochondria by simply modifying the Pi concentration in the media and 2) easily follow the content of this natural non-labeled lipid inside mitochondria by classical methods of lipid analysis such as mass spectrometry or thin layer chromatography. Thus, by looking for mitochondria complexes enriched in DGDG during Pi starvation, we identified on Clear Native Polyacrylamide Gel (CN-PAGE) a super-complex called Mitochondrial Transmembrane Lipoprotein complex (MTL) $[8,10]$. The MTL complex is present in cells grown in presence or in absence of Pi. Proteomic analyses have revealed the presence in this complex of proteins located mostly in the mitochondria membranes [8]. However, some components are also located in other cell compartments such as plastids, suggesting the presence of the MTL complex at membrane contact sites. Furthermore, this complex is dynamic and both its lipid and protein composition vary during Pi starvation. Among this complex, a protein localized in the inner membrane of mitochondria, AtMic60, has been further investigated for a putative role in lipid trafficking $[8,10]$.

This protocol describes the strategy used to reveal the key role of AtMic60 in mitochondria lipid remodeling during Pi starvation [8]. We started from callus cell cultures that allow to easily obtain liquid cultured cell lines from mutant plants. After purification of mitochondria from atmic60 mutant callus, the involvement of AtMic 60 on lipid trafficking is investigated by analyzing 1) the in vitro incorporation of radiolabeled DGDG inside the MTL complex and 2) the lipidome of the MTL complex compared to the lipidome of mitochondria membranes (Figure 1).

\section{Materials}

Prepare all reagents and media with ultrapure water. For cell cultures, always work in sterile condition under a laminar flow hood. For lipid extraction and analysis, always use glass vessels and never plastic with organic solvents. Wash all vessels without detergent but with distilled water, then ethanol. All solvents must be for Analysis grade except Hexane that must be for GC grade. Chloroform should be ethanol stabilized. Diligently follow all waste disposal regulations when disposing waste materials.

\subsection{Plant material and culture}

1. Arabidopsis thaliana Col0 plants are used as wild type (WT). A TDNA insertion line (SALK_087650c) [11] in AtMic60 gene (AT4G39690) in Col0 background is used as an example to study a defect in lipid trafficking [8].

2. MS +Pi: $4.41 \mathrm{~g} / \mathrm{L}$ Murashige and Skoog (MS) basal salts, 1X MS

Vitamin Solution, $1.5 \%$ (w/v) sucrose, $1.2 \mathrm{mg} . \mathrm{L}^{-1} 2,4-$ 
dichlorophenoxyacetic acid. The $\mathrm{pH}$ is adjusted to 5.7 with $\mathrm{NaOH}$ and the media is autoclaved.

3. MS -Pi: $4.41 \mathrm{~g} / \mathrm{L}$ MS basal salts without Pi, 1X MS Vitamin Solution, $1.5 \%(\mathrm{w} / \mathrm{v})$ sucrose, $1.2 \mathrm{mg} . \mathrm{L}^{-1}$ 2,4-dichlorophenoxyacetic acid. The $\mathrm{pH}$ is adjusted to 5.7 with $\mathrm{NaOH}$ and the media is autoclaved.

4. MS seedlings: $4.41 \mathrm{~g} / \mathrm{L}$ MS with basal salts and vitamins, $0.5 \%$ (w/v) sucrose and $0.5 \mathrm{~g} / \mathrm{L}$ MES. The $\mathrm{pH}$ is adjusted to 5.7 with $\mathrm{KOH}$, agar is added at $0.8 \%(\mathrm{w} / \mathrm{v})$ and the media is autoclaved.

5. MS callus: $4.41 \mathrm{~g} / \mathrm{L} \mathrm{MS,} 3 \%(\mathrm{w} / \mathrm{v})$ sucrose and $1.2 \mathrm{mg} . \mathrm{L}^{-1}$ of $2,4-$ dichlorophenoxyacetic acid. The $\mathrm{pH}$ is adjusted to 5.7 with $\mathrm{KOH}$, agar is added at $0.8 \%(\mathrm{w} / \mathrm{v})$ and the media is autoclaved.

6. Ethanol $70 \%(\mathrm{v} / \mathrm{v})$.

7. Sterilization solution: bleach $0.4 \%$ active chlorine in water.

8. Agarose $0.2 \%(\mathrm{w} / \mathrm{v})$ in water. The solution is autoclaved.

9. Sterile ultrapure water (prepared by purifying deionized water, to attain a sensitivity of $18 \mathrm{M} \Omega-\mathrm{cm}$ at $25^{\circ} \mathrm{C}$ ).

\subsection{Mitochondria purification from callus liquid cultures}

1. Grinding buffer: $0.3 \mathrm{M}$ mannitol, $15 \mathrm{mM}$ 3-(Nmorpholino)propanesulfonic acid (MOPS) $\mathrm{pH} 8,2 \mathrm{mM}$ ethylene glycolbis(2-aminoethylether)-N,N,N',N'-tetraacetic acid (EGTA) pH 8, 0.6 $\%$ (w/v) polyvinylpyrrolidone K25 (PVP25). Just before use, $0.5 \%$ (w/v) bovine serum albumin (BSA), $1 \mathrm{mM}$ dithiothreitol (DTT), $1 \mathrm{mM}$ phenylmethylsulfonyl fluoride (PMSF), $5 \mathrm{mM}$ aminocaproic acid and 1 $\mathrm{mM}$ benzamidine are added.

2. Washing buffer: $0.3 \mathrm{M}$ mannitol, $10 \mathrm{mM}$ MOPS pH 7.4. Just before use, $1 \mathrm{mM}$ PMSF, $5 \mathrm{mM}$ aminocaproic acid and $1 \mathrm{mM}$ benzamidine are added.

3. CX2: $0.6 \mathrm{M}$ mannitol, $20 \mathrm{mM}$ MOPS pH 7.2, 2 mM EGTA. Just before use, $0.2 \%(\mathrm{w} / \mathrm{v}) \mathrm{BSA}$ is added.

4. Percoll 40: $40 \%$ (v/v) Percoll (GE Healthcare Life Sciences), 1X of CX2.

5. Percoll 28: $28 \%$ (v/v) Percoll (GE Healthcare Life Sciences), 1X of CX2.

6. Percoll 23: $23 \%$ (v/v) Percoll (GE Healthcare Life Sciences), 1X of CX2.

7. Mortar and pestle.

8. Sand.

9. $50 \mathrm{~mL}$ polycarbonate tubes.

\subsection{Galactoglycerolipid labelling and transfer with UDP-[14 $C]-$ galactose}

1. UDP- $\left[{ }^{14} \mathrm{C}\right]$-galactose: $10 \mathrm{mM}$ UDP- $\left[{ }^{14} \mathrm{C}\right]$-galactose $167 \mathrm{bq} / \mathrm{nmol}$

2. Washing buffer: 0.3 M mannitol, $10 \mathrm{mM}$ MOPS pH 7.4. 


\subsection{Mitochondria membranes purification and solubilization}

1. Swelling buffer: $10 \mathrm{mM}$ MOPS $\mathrm{pH}$ 7.4. Just before use, $1 \mathrm{mM}$ PMSF, $5 \mathrm{mM}$ aminocaproic acid and $1 \mathrm{mM}$ benzamidine are added.

2. Membrane buffer: $50 \mathrm{mM}$ imidazole $\mathrm{pH} 7,0.5 \mathrm{M}$ aminocaproic acid, 1 mM EDTA pH 8.

3. DDM $1 \%$ : A stock solution $10 \%(\mathrm{w} / \mathrm{v})$ of $\mathrm{n}$-dodecyl $\beta$-D-maltoside (DDM) is prepared in water. Then, this solution is diluted 10 times in water to obtain a DDM $1 \%(\mathrm{w} / \mathrm{v})$ solution stored at $-20^{\circ} \mathrm{C}$.

4. Loading buffer 5X: $300 \mathrm{mM}$ Tris- $\mathrm{HCl} \mathrm{pH}$ 6.8, $50 \%$ (v/v) glycerol, $0.5 \%(\mathrm{w} / \mathrm{v})$ bromophenol blue in water. Store at $-20^{\circ} \mathrm{C}$.

\subsection{CN-PAGE}

Prepare the gel mix just before use.

1. Concentration gel: $3 \%$ acrylamide/bis-acrylamide 37.5/1 (stock solution at $30 \%$, Bio-Rad), $0.125 \mathrm{M}$ Tris-HCl pH 6.8, $0.01 \%(\mathrm{w} / \mathrm{v})$ ammonium persulfate (APS), $0.04 \%(\mathrm{v} / \mathrm{v}) \mathrm{N}, \mathrm{N}, \mathrm{N}^{\prime}, \mathrm{N}^{\prime}-$ tetramethylethane-1,2-diamine (TEMED). Add the TEMED just before pouring the gel.

2. Separation gel 3.5\%: $3.5 \%$ acrylamide/bis-acrylamide 37.5/1 (stock solution at $30 \%$, Bio-Rad), $0.125 \mathrm{M}$ Tris- $\mathrm{HCl} \mathrm{pH} 8.8,0.01 \%(\mathrm{w} / \mathrm{v})$ APS, $0.04 \%(\mathrm{v} / \mathrm{v})$ TEMED. Add the TEMED just before pouring the gel

3. Separation gel $12 \%: 12 \%$ acrylamide/bis-acrylamide 37.5/1 (stock solution at $30 \%$, Bio-Rad), $0.125 \mathrm{M}$ Tris-HCl pH 8.8, $0.01 \%(\mathrm{w} / \mathrm{v})$ APS, $0.04 \%(\mathrm{v} / \mathrm{v})$ TEMED. Add the TEMED just before pouring the gel

4. Migration buffer: Prepare a 5X solution composed of $0.25 \mathrm{M}$ Tris, $1.92 \mathrm{M}$ glycine, $\mathrm{pH} 8.3$ with $\mathrm{HCl}$. Store the solution at $4^{\circ} \mathrm{C}$. Dilute 5 times this solution in MilliQ water just before use to obtain the Migration buffer.

5. Gradient Mixer $15 \mathrm{~mL}$.

6. Peristatic pump.

\subsection{Fixation and staining of CN-PAGE}

1. Fixation solution: $40 \%$ (v/v) ethanol, $10 \%$ (v/v) acetic acid.

2. Staining solution: $34 \%(\mathrm{v} / \mathrm{v})$ methanol, $17 \%(\mathrm{w} / \mathrm{v})$ ammonium sulfate, $0.5 \%$ (v/v) acetic acid, $0.1 \%(\mathrm{w} / \mathrm{v})$ Coomassie blue G250.

3. Ultrapure water (prepared by purifying deionized water, to attain a sensitivity of $18 \mathrm{M} \Omega-\mathrm{cm}$ at $25^{\circ} \mathrm{C}$ ).

\subsection{Lipid extractions}

1. Corex tubes $15 \mathrm{~mL}$ high strength.

2. Boiling ethanol. 
3. Methanol:chloroform 1:2(v/v)

4. Quartz wool (see Note 1).

5. Potters pestles (see Note 2).

6. Evaporator under argon (see Note 3).

7. Ultrapure water (prepared by purifying deionized water, to attain a sensitivity of $18 \mathrm{M} \Omega-\mathrm{cm}$ at $25^{\circ} \mathrm{C}$ ).

8. $\mathrm{NaCl} 1 \%(\mathrm{w} / \mathrm{v})$ in ultrapure water.

9. Hemolysis glass tube for single use.

\subsection{Methanolysis}

1. PYREX® tubes of $20 \mathrm{~mL}(160 \mathrm{~mm} \times 16 \mathrm{~mm})$, tubes in borosilicate glass (high thermal resistance) with screw top. Screw caps in phenolic resin with rubber seal lined with inert PTFE.

2. Standard C15 (fatty acid with 15 carbons) solution: powder of pentadecanoic acid (99\%), stored at RT. Prepare a solution at 0.5 $\mathrm{mg} / \mathrm{mL}$ in chloroform/methanol $(1 / 2, \mathrm{v} / \mathrm{v})$ (see Note 4$)$.

3. Dry hot bath.

4. Methanolysis buffer: Sulfuric acid $\left(\mathrm{H}_{2} \mathrm{SO}_{4} 24 \mathrm{~N}\right) 2.5 \%$ in methanol $(\mathrm{v} / \mathrm{v})($ see Note 5$)$.

5. Ultrapure water (prepared by purifying deionized water, to attain a sensitivity of $18 \mathrm{M} \Omega-\mathrm{cm}$ at $25^{\circ} \mathrm{C}$ ).

6. Hexane for GC analysis

7. Hemolysis glass tube for single use.

\subsection{Total fatty acid quantification by Gas Chromatography - Flame Ionisation Detector (GC-FID)}

1. Vials for automatic sampler with an insert of $250 \mu \mathrm{L}$ and screw caps 9 mm with PTFE seal.

2. Hexane for GC analysis.

3. Column BPX70 (70\% Cyanopropyl Polysilphenylene-siloxane) for GC: length $30 \mathrm{~m}$, internal diameter $0.22 \mathrm{~mm}$, film thickness $0.25 \mu \mathrm{m}$.

4. Gas Chromatography - Flame Ionisation Detector

5. Commercial FAME standard solution to calibrate the GC-FID retention time

\subsection{Lipid class quantification by liquid chromatography - mass spectrometry (LC-MS)}

1. Internal standard solution: prepare $1 \mathrm{~mL}$ of stock solution for each internal standard at $1.25 \mathrm{mM}$ in chloroform/methanol [2/1, (v/v)] (see Note 6). Internal standards were obtained from Avanti Polar Lipids Inc. for PE 18:0-18:0 and PC 18:0-18:0. DGDG 16:0/16:0 was synthesized chemically [12]. As an alternative, DGDG 18:0/18:0 can be obtained from purchased natural extract (Avanti Polar Lipids Inc.) and hydrogenated (see Note 7).To prepare the internal standard solution, in a volumetric flask of $50 \mathrm{~mL}$, add $50 \mu \mathrm{L}$ of each individual standard and 
complete to $50 \mathrm{~mL}$ with chloroform/methanol [2/1, (v/v)]. Aliquot the solution by $1 \mathrm{~mL}$ in hermetically sealed vials and store at $-20^{\circ} \mathrm{C}$.

2. Hemolysis glass tube for single use.

3. Evaporator under argon (see Note 3).

4. High Pressure Liquide Chromatography (HPLC) coupled to a triple quadripole mass spectrometer (see Note 8).

\section{Methods}

\subsection{Preparation of callus liquid cultures}

1. Put around 20 seeds from WT and mutant plants in a $2 \mathrm{~mL}$ Eppendorf tube for sterilization.

2. Add $1 \mathrm{~mL}$ of ethanol $70 \%$ and incubate the seeds $2 \mathrm{~min}$ at room temperature under agitation.

3. Discard ethanol and add $1 \mathrm{~mL}$ of Sterilization solution (see Note 9)

4. Incubate $12 \mathrm{~min}$ at room temperature under agitation.

5. Discard the Sterilization solution and wash the seeds 4 times with 1 $\mathrm{mL}$ of sterile water.

6. Resuspend the seeds in $100 \mu \mathrm{L}$ of Agarose $0.2 \%$.

7. Spread the seeds one by one on MS seedling plates with a pipette, tape the plates with a porous adhesive and allow the stratification of the seeds on dark at $4^{\circ} \mathrm{C}$ for $48 \mathrm{H}$.

8. Incubate the plates under long day condition (16h light/8h dark) at $22^{\circ} \mathrm{C}$ for 2 weeks.

9. Carefully cut with a sterile razor leaves from seedlings and place them on MS callus plates with the epidermal layer contacting the media.

10. Incubate the plates under continuous light. Callus will be formed after 4 to 5 weeks.

11. To maintain callus, every four weeks, cut small pieces of callus with a sterile razor blade and transfer them on a new MS callus plate.

12. To obtain liquid cultures, add around ten 4 weeks-old callus in 200 $\mathrm{mL}$ of $\mathrm{MS}+\mathrm{Pi}$ and incubate under continuous light at $22^{\circ} \mathrm{C}$ on a rotary shaker at $125 \mathrm{rpm}$. Callus are then sub-cultured every 7 days in $200 \mathrm{~mL}$ of MS +Pi (see Note 10).

13. For one experiment, $5 \mathrm{~mL}$ of sedimented callus (see Note 10) of 7 days old cultures are washed 3 times with MS +Pi or MS -Pi media in a $50 \mathrm{~mL}$ sterile tube and used to inoculate $200 \mathrm{~mL}$ of $\mathrm{MS}+\mathrm{Pi}$ or MS $\mathrm{Pi}$ media in a 1L flask. For a typical experiment, 3 flasks of MS +Pi and 4 flasks of MS -Pi are inoculated. To compare the results, experiments from $\mathrm{Col} 0$ and atmic 60 grown in presence and absence of phosphate are performed the same day, meaning that 4 mitochondria purifications are performed in the same time. 
14. Callus are grown on continuous light under agitation at $125 \mathrm{rpm}$ for 4 days to be in exponential phase of lipid remodeling for mitochondria purification.

\subsection{Mitochondria purification from callus liquid cultures}

To preserve mitochondria integrity and functions, each step of purification has to be performed at $4^{\circ} \mathrm{C}$ with all materials (mortar, tubes, rotors...) and buffers pre-chilled at $4^{\circ} \mathrm{C}$. Mitochondria have to be manipulated carefully. Particularly, during resuspension steps, cut tips have to be used (see Note 11).

1- Filter each cell flask on round Wattman filter paper using a filtration unit. Cells are weighted and placed on a mortar (see Note 12). Typically, we obtain around $10 \mathrm{~g}$ and $8 \mathrm{~g}$ of callus grown for 4 days in $\mathrm{MS}+\mathrm{Pi}$ or MS -Pi respectively.

2. In a cold room, add $30 \mathrm{~mL}$ of Grinding buffer and $15 \mathrm{~mL}$ of sand for $64 \mathrm{~g}$ of callus in the mortar. Grind the cells with a pestle until obtaining a homogenous suspension. This takes generally 6 to $8 \mathrm{~min}$ to obtain a complete grinding.

3. Add Grinding buffer $(20 \mathrm{~mL})$ to the lysate to facilitate the transfer into $500 \mathrm{~mL}$ centrifuge bottles. Further wash the mortar with $20 \mathrm{~mL}$ of Grinding buffer.

4. Centrifuge cell lysates at $700 \times g 5 \mathrm{~min}$ at $4^{\circ} \mathrm{C}$ to pellet unbroken cells, heavy material and sand.

5. Centrifuge the supernatant 2 times at $3000 \times g 5 \mathrm{~min}$ at $4^{\circ} \mathrm{C}$ in $50 \mathrm{~mL}$ polycarbonate centrifuge tubes.

6. Pellet crude mitochondria by a centrifugation of the supernatant at 20 $000 \times \mathrm{g}$ during $15 \mathrm{~min}$ at $4^{\circ} \mathrm{C}$.

7. Carefully resuspend mitochondria in $2 \mathrm{~mL}$ of Washing buffer using a paintbrush and completely dissociate the mitochondria in a $5 \mathrm{~mL}$ Potter homogenizer by 3 gentle strokes. Use cut tips to manipulate crude mitochondria.

8. Prepare four discontinuous percoll gradients (one for each condition): pour $5 \mathrm{~mL}$ of Percoll 40 at the bottom of $32 \mathrm{~mL}$ ultracentrifuge tubes for swinging rotor. Then, gently add $20 \mathrm{~mL}$ of Percoll 23 and $10 \mathrm{~mL}$ of Percoll 18 (see Note 13). The three layers should be clearly visible.

9. Add carefully $2 \mathrm{~mL}$ of crude mitochondria on the top of each gradient with a pipette.

10. Centrifuge at $70000 \times g$ for $45 \mathrm{~min}$ at $4^{\circ} \mathrm{C}$ in a swinging rotor, with standard acceleration at the beginning of the run but a slow deceleration at the end to preserve the gradient layers.

11. After centrifugation, mitochondria are located at the 32/40\% interface (see Note 14).

12. Carefully aspirate and discard the upper part of the gradient.

13. Pipette the mitochondria fraction and place them in a $50 \mathrm{~mL}$ polycarbonate centrifuge tube (one per gradient). Fill the tube with Washing buffer.

14. Centrifuge at $20000 \times \mathrm{g} 15 \mathrm{~min}$ at $4^{\circ} \mathrm{C}$. 
15. Carefully discard the supernatant (see Note 15). Fill the tubes with Washing buffer and centrifuge again at $20000 \times \mathrm{g} 15 \mathrm{~min}$ at $4^{\circ} \mathrm{C}$.

16. Discard the supernatant and resuspend carefully the pellet in $2 \mathrm{~mL}$ of Washing buffer.

17. Mitochondria are then transferred in $2 \mathrm{~mL}$ microfuge tubes and centrifuge at $12000 \times \mathrm{g} 10 \mathrm{~min}$ at $4^{\circ} \mathrm{C}$.

18. Resuspend mitochondria in 100 to $200 \mu \mathrm{L}$ of Washing buffer and determine the concentration of mitochondria in equivalent protein by Bradford [13].

\subsection{Galactoglycerolipid labelling and transfer with UDP-[14C]-galactose (Figure 1.1)}

1. The incorporation of UDP- $\left[{ }^{14} \mathrm{C}\right]$-galactose in the MTL complex is performed in a final volume of $250 \mu \mathrm{L}$ of Washing buffer containing $750 \mu \mathrm{g}$ of mitochondria proteins, $1 \mathrm{mM}$ DTT and $1 \mathrm{mM} \mathrm{MgCl}_{2}$.

2. To start the reaction, add UDP- $\left[{ }^{14} \mathrm{C}\right]$-galactose at a final concentration of $1 \mathrm{mM}$ (see Note 16).

3. Incubate the samples for $30 \mathrm{~min}$ at $22^{\circ} \mathrm{C}$.

4. To eliminate unincorporated UDP- $\left[{ }^{14} \mathrm{C}\right]$-galactose, pellet the mitochondria by a centrifugation of $10 \mathrm{~min}$ at $12000 \mathrm{xg}$ at $4^{\circ} \mathrm{C}$.

5. Discard the supernatant and resuspend the mitochondria in $500 \mu \mathrm{L}$ of Washing buffer.

\subsection{Membrane purification and complex solubilization}

1. Mitochondria membranes are broken using osmotic choc. After the last wash, transfer the mitochondria (radiolabeled or not) in a $1.5 \mathrm{~mL}$ ultracentrifuge tube and pellet mitochondria $10 \mathrm{~min}$ at $12000 \mathrm{x} \mathrm{g}$ at $4^{\circ} \mathrm{C}$.

2. Resuspend the mitochondria in $1 \mathrm{~mL}$ of Swelling buffer and incubate 5 min on ice.

2. Mitochondria breakage is achieved by mixing the mitochondria for 10 seconds at $500 \mathrm{rpm}$ with a shaker.

3. Pellet the membranes by a centrifugation at $100000 \times \mathrm{g} 20 \mathrm{~min}$ at $4^{\circ} \mathrm{C}$.

4. After centrifugation, discard the supernatant and resuspend the membranes in 30 to $50 \mu \mathrm{L}$ of Membrane buffer for labeling experiment (Figure 1-1) or in 100 to $300 \mu \mathrm{L}$ for lipidomic analyses (Figure 1-2).

5. Estimate the concentration of mitochondria membrane proteins by Bradford [13]. We usually obtain around $50-100 \mu \mathrm{g}$ of mitochondria membrane proteins per $\mathrm{g}$ of callus.

6. To isolate and analyze the MTL complex, mitochondria complexes are then solubilized with DDM. Membranes containing $20 \mu \mathrm{g}$ of proteins are solubilized and loaded in one lane of CN-PAGE (see Note 17). For lipidomic analysis of the MTL complex, complexes from 4 lanes will be pooled, meaning that $80 \mu \mathrm{g}$ of membrane proteins have to be solubilized per experiment. For membranes containing $20 \mu \mathrm{g}$ of proteins, the solubilization is performed in a total volume of $20 \mu \mathrm{L}$ of 
Membrane buffer by the addition of DDM at a final concentration of $1.5 \mu \mathrm{g} / \mu \mathrm{g}$ of membrane proteins in a $1.5 \mathrm{~mL}$ ultracentrifuge tube (see Note 18).

8. The solubilization is achieved by pipetting slowly the mix 30 times followed by an incubation of $5 \mathrm{~min}$ on ice.

9. After incubation, pellet the insoluble materials by a centrifugation of $20 \mathrm{~min}$ at $100000 \mathrm{x} g$ at $4^{\circ} \mathrm{C}$.

10. After centrifugation, carefully pipette the supernatant without touching the pellet and mix it with Loading buffer $5 \mathrm{X}(5 \mu \mathrm{L}$ for $20 \mu \mathrm{L}$ of supernatant).

\subsection{Isolation of the MTL complex by CN-PAGE}

\subsubsection{Preparation of the CN-PAGE}

1. The native gels are prepared in a Bio-Rad Mini-Protean ${ }^{\circledR}$ gel system with $1 \mathrm{~mm}$ glass plates (see Note 19).

2. A 15-mL gradient mixer and a peristaltic pump are used to cast the gel. Put the chamber on a magnetic stirrer. Link the first chamber of the gradient mixer to the peristaltic pump. Before use, wash the gradient mixer and the pump with $30 \mathrm{~mL}$ of ultrapure water. Then, close the connections between the chamber 1 and the pump and between the two chambers and fixe the end of the pump tube on the top of the glass plates.

3. Add a small magnetic stir bar in the first chamber.

4. For one gel, prepare $3 \mathrm{~mL}$ of Separation gel $12 \%$ and $3.5 \mathrm{~mL}$ of Separation gel $3.5 \%$.

5. Right away after the addition of TEMED, load $2 \mathrm{~mL}$ of Separation gel $12 \%$ and $2.5 \mathrm{~mL}$ of Separation gel $3.5 \%$ in the first and second chamber respectively and turn on the stirrer in the first chamber (see Note 20).

6. Turn on the pump (flux of $3 \mathrm{~mL} / \mathrm{min}$ ), open the connection between the chamber 1 and the pump tube and immediately open the connection between the chambers to allow the formation of the gradient. Wait until all the separation gel fills the glass plates. Normally, with these volumes of separation gels, about $1 \mathrm{~cm}$ remains at the top of the gel to allow the addition of the Concentration gel.

7. Carefully add water at the top of the gel to form a straight line of separation gel. Wait about an hour for the polymerization of the separation gel.

8. Eliminate the water by inversion of the gel on a paper.

9. Prepare (around $2 \mathrm{~mL}$ ) and pour immediately the Concentration gel on top of the separation gel and add a 10 wells comb avoiding air bubble formation. Wait about an hour for the polymerization.

\subsubsection{Loading of samples and separation of the complexes}

1. Place the gel in the migration tank and add the Migration buffer. 
2. Gently clean the wells and add the samples ( $25 \mu \mathrm{L} /$ well) (see Note 21).

3. Operate the migration of the gel at $80 \mathrm{~V}$ until the bromophenol blue reach the bottom of the gel. It takes around $2 \mathrm{~h}$ to $2 \mathrm{~h} 30$ (see Note 22).

\subsubsection{Fixation and staining of CN-PAGE}

1. After the migration of the native gel, remove the gel from the glass plates and cut the concentration gel. Fixe the gel in $25 \mathrm{~mL}$ of Fixation solution for at least $30 \mathrm{~min}$ at room temperature (see Note 23).

2. After the fixation, replace the Fixation solution with $25 \mathrm{~mL}$ of Staining solution and incubate overnight at room temperature (see Note 24).

3. Discard the Staining solution and wash the gel with several incubations at room temperature with ultrapure water.

4. The MTL complex appears as a wavy band around $800 \mathrm{KDa}$ (Figure 2, coomassie). In Col0, a decrease of the MTL complex molecular weight is observed in -Pi compared to $+\mathrm{Pi}$. However, a smaller shift of the MTL complex is observed in atmic60 callus suggesting an impairment in MTL complex remodeling during Pi starvation.

\subsection{Analysis of $\left[{ }^{14} \mathrm{C}\right]-D G D G$ incorporation into the MTL complex}

1. If an UDP-[ $\left[{ }^{14} \mathrm{C}\right]$-galactose labelling have been performed (Figure 11 ), dry the gel on a Wattman paper for $2 \mathrm{~h}$ using a gel dryer.

2. Expose the dried gel with a phosphoimager screen and reveal the radioactive signal with a laser scanner (see Note 25). Usually, a gel to screen exposure of 3 days is enough to visualize the radiolabeled galactoglycerolipids present in the MTL complex (Figure 2, $\left[{ }^{14} \mathrm{C}\right]$ labelling). In a typical experiment for Col0, an increase by a factor 2 of the radioactive signal is observed in the MTL complex in $-\mathrm{Pi}$ compared to $+\mathrm{Pi}$ (Figure 2, $\left[{ }^{14} \mathrm{C}\right]$ labelling) [8]. In atmic60 callus, a decrease in the incorporation of $\left[{ }^{14} \mathrm{C}\right]$-galactoglycerolipids is observed in the MTL complex in -Pi compared to Col0 callus (Figure 2, $\left[{ }^{14} \mathrm{C}\right]$ labelling). These results indicate that the rate of incorporation of DGDG into the MTL complex is altered in absence of AtMic60, suggesting an involvement of AtMic60 in lipid trafficking during Pi starvation.

\subsection{Analysis of the lipid composition of mitochondria membranes and of the MTL complex}

\subsubsection{Lipids extraction from mitochondria membranes}

1. Start the lipid extraction from a pellet of mitochondria membranes containing at least $200 \mu \mathrm{g}$ of proteins prepared in part 3.4.5 (see Note 26).

2. Warm up a water bath with a hot block inside. Experiment can start when the water is above $80^{\circ} \mathrm{C}$. In the same time, warm up an 
Erlenmeyer flask closed with double aluminum foil containing $25 \mathrm{~mL}$ of absolute ethanol until it boils.

3. Lipid extraction: resuspend the mitochondria membranes in $1 \mathrm{~mL}$ of boiling ethanol, mix by pipetting and transfer the mitochondria membrane in a hemolysis tube.

4. Close the tube with double aluminum foil and dispose the tube in the hot block in the water bath for $5 \mathrm{~min}$ with some shaking with a pestle (see Note 27). This step will inhibit phospholipase D activity.

5. Remove the tube from the hot block, check the ethanol volume left in the tube and if necessary complete up to $1 \mathrm{ml}$ with boiling ethanol. Add $0.5 \mathrm{~mL}$ of methanol to rinse the pestle directly in the tube. Remove the pestle and add $2 \mathrm{~mL}$ of chloroform. Blow argon in the solvent mixture to remove oxygen during 1 minute (see Note 28). Close the tube with foil and leave it for $1 \mathrm{~h}$ at room temperature.

6. Filter the liquid in a $15 \mathrm{~mL}$ Corex tube with a funnel plugged with ethanol washed glass wool to remove cell debris. Add $0.75 \mathrm{~mL}$ of chloroform:methanol $(2: 1(\mathrm{v} / \mathrm{v}))$ in the Corex tube containing the cell debris to rinse it and pour the liquid in the funnel.

7. Remove the funnel and add $1.25 \mathrm{~mL}$ of $\mathrm{NaCl} 1 \%$ to the filtrate mixture. Blow argon inside the tube to mix up solvents during 1 minute and centrifuge $10 \mathrm{~min}$ at $1000 \mathrm{x} g$ to separate the organic and aqueous phase.

8. Collect the lower phase (organic phase) with a Pasteur pipette (see Note 29) and transfer it in a clean hemolysis glass tube. Dry all the solvents by blowing argon on top of the liquid.

9. Rinse the tube with $200 \mu \mathrm{L}$ of chloroform and dry lipids by blowing argon on top of the liquid. Close the tube and store the lipid extract at $20^{\circ} \mathrm{C}$. Lipid extracts are stable for several months.

\subsubsection{Lipids extraction from CN-PAGE}

1. To perform a lipidomic analysis of the MTL complex (Figure 1-2), cut 4 bands of MTL complex per samples (equivalent of $80 \mu \mathrm{g}$ of proteins of solubilized membranes) and pool them in a $5 \mathrm{~mL}$ hemolysis glass tube (see Note 30). As a control, two other bands located in different parts of the gel and a band corresponding to a lane without any protein are also cut for analysis and treated as the MTL complex sample (Figure 3A).

2. The lipids are then extracted with a protocol adapted from Bligh and Dyer [14]. Add $500 \mu \mathrm{L}$ of $\mathrm{H}_{2} \mathrm{O}$ and $1.875 \mu \mathrm{L}$ of chloroform:methanol $1: 2(\mathrm{v} / \mathrm{v})$ on the acrylamide bands.

3. Vortex and incubate the samples for $1 \mathrm{~h}$ at room temperature under agitation to extract the lipids from the gel.

4. Add $625 \mu \mathrm{L}$ of $\mathrm{H}_{2} \mathrm{O}$ and $625 \mu \mathrm{L}$ of chloroform to promote the formation of the biphase.

5. Vortex and centrifuge the tubes $5 \mathrm{~min}$ at $1000 \mathrm{x} g$.

6. Transfer the lower organic phase in a new hemolysis tube and dry it under argon. 
7. Perform a second extraction on the aqueous phase with $625 \mu \mathrm{L}$ of chloroform.

8. After centrifugation $5 \mathrm{~min}$ at $1000 \mathrm{x} g$, pool the second organic phase with the first one and dry the lipids under argon. Lipids can be stored dried at $-20^{\circ} \mathrm{C}$ before analysis by mass spectrometry.

\subsubsection{Production of fatty acid methyl esters (FAMEs) from glycerolipids and free fatty acids by transesterification with methanol (methanolysis)}

This step is performed only for lipids extracted from mitochondria membranes to estimate the quantity of lipids that will be used for mass spectrometry analysis. The quantity of lipids extracted from CN-PAGE is too low and all the extracted lipids will be used for mass spectrometry analysis.

1. Turn on the hot block at $100^{\circ} \mathrm{C}$ and pre-warm an aliquot of standard C15 solution (see Note 31).

2. Resuspend the lipid extract in $500 \mu \mathrm{L}$ of chloroform. Uptake $50 \mu \mathrm{L}$ of the lipid extract and transfer it into the methanolysis tube.

3. With a Hamilton syringe, add $10 \mu \mathrm{L}$ of $\mathrm{C} 15$ solution ( $5 \mu \mathrm{g} / \mathrm{tube})$ in the methanolysis tube.

4. Add $3 \mathrm{~mL}$ of methanolysis buffer in all the methanolysis tubes. In each tube there are: $10 \mu \mathrm{L}$ of $\mathrm{C} 15$ solution, $50 \mu \mathrm{L}$ of lipid extract and the methanolysis buffer. Close tightly the glass tube, vortex briefly and incubate $1 \mathrm{~h}$ at $100^{\circ} \mathrm{C}$ for the methanolysis reaction (esterification reaction) to occur.

5. Take the tube out of the hot block $5 \mathrm{~min}$ at room temperature to cool down the tube. Stop the reaction by adding $3 \mathrm{~mL}$ of water.

6 . Add $3 \mathrm{~mL}$ of hexane to extract the FAMEs and vortex vigorously. Wait at least $20 \mathrm{~min}$ at room temperature to allow the biphase to form correctly. At this step, biphase can be stored a few days at $4^{\circ} \mathrm{C}$ if necessary. Take the upper phase (hexane phase) containing the FAMEs and transfer it in a hemolysis glass tube, dry it under argon.

7. Repeat step 6 to re-extract FAMEs from the methanol-water phase by adding again $3 \mathrm{~mL}$ of hexane in the methanolysis tube. Pour the upper phase in the same hemolysis glass tube than the one used in step 6 and dry it under argon.

8. To concentrate the FAMEs at the bottom of the glass tube, rinse the tube wall with $200 \mu \mathrm{L}$ of hexane. Allow the liquid to rest at the bottom of the tube and dry it gently under argon.

9. Store the FAMEs at $-20^{\circ} \mathrm{C}$ or proceed with GC analysis. (GC-FID)

3.7.4 Quantification of FAMEs by Gas Chromatography - Flame Ionisation Detector

1. Resuspend the FAMEs in $50 \mu \mathrm{L}$ of hexane and transfer the FAMEs in an insert vial. Seal the vial tightly to avoid evaporation.

2. Inject $2 \mu \mathrm{L}$ of the sample in the GC-FID on a BPX70 column. Nitrogen is used as carrier gas with $3.5 \mathrm{~mL} / \mathrm{min}$ constant flow 
compensation, split ratio is $13.3: 1$, injection temperature of $200^{\circ} \mathrm{C}$, detector temperature of $280^{\circ} \mathrm{C}$ and the oven temperature range start at $130^{\circ} \mathrm{C}$, hold for $7.5 \mathrm{~min}$ at $130^{\circ} \mathrm{C}$, ramp up to $180^{\circ} \mathrm{C}$ at $3^{\circ} \mathrm{C} / \mathrm{min}$, and hold $10 \mathrm{~min}$ at $180^{\circ} \mathrm{C}$. This will allow FAMEs separation from $12 \mathrm{C}$ up to $24 \mathrm{C}$ in function of the chain length and the number of desaturation.

3. Each FAME is identified by comparison of its retention times with those of standards. FID response is dependent of the mass of the FAME therefore each FAME will be quantified by the surface peak method using $\mathrm{C} 15$ surface peak for calibration with the following equation:

$$
\text { Quantity in } \mu g \text { of FAME }=\frac{\text { Area of FAME peak } \times \text { Quantity in } \mu g \text { of } C 15(5 \mu g)}{\text { Area of C15 peak }}
$$

4. By adding each FAME quantity and taking into account the volume used for the methanolysis, GC-FID analysis gives the total fatty acid content of the lipid extract in $\mu \mathrm{g}$ as well as its fatty acid composition. Fatty acid content in nmol can be established taking into account the molecular mass of each fatty acid.

\subsubsection{Quantification of lipid molecules by LC/MS/MS}

1. All the lipid extracted from CN-PAGE or $25 \mathrm{nmol}$ of fatty acids from mitochondria membranes lipid extract are dissolved in $100 \mu \mathrm{L}$ of Internal standard solution.

3. Lipids are then separated by HPLC and quantified by ESI-MS/MS. Lipid classes are separated using an HPLC system on a $150 \mathrm{~mm} \times 3 \mathrm{~mm}$ (length $\times$ internal diameter) $5 \mu \mathrm{m}$ diol column at $40^{\circ} \mathrm{C}$. The mobile phases consisted of hexane/isopropanol/water/ammonium acetate $1 \mathrm{M}$, pH5.3 [625/350/24/1, (v/v/v/v)] (A) and isopropanol/water/ammonium acetate 1M, pH5.3 [850/149/1, (v/v/v)] (B). The injection volume is 20 $\mu \mathrm{L}$, corresponding to $5 \mathrm{nmol}$ of total fatty acid (see Note 32 ), and each sample is injected 3 times as technical replicates. After $5 \mathrm{~min}$, the percentage of B was increased linearly from $0 \%$ to $100 \%$ in $30 \mathrm{~min}$ and stayed at $100 \%$ for $15 \mathrm{~min}$. This elution sequence was followed by a return to $100 \% \mathrm{~A}$ in $5 \mathrm{~min}$ and an equilibration for $20 \mathrm{~min}$ with $100 \%$ A before the next injection, leading to a total runtime of $70 \mathrm{~min}$. The flow rate of the mobile phase is $200 \mu \mathrm{L} / \mathrm{min}$ (see Note 33).

4. Mass spectrometric analysis is done on a triple quadripole mass spectrometer (see Note 34). The quadrupoles Q1 and Q3 were operated at widest and unit resolution respectively. Specific MRM (Multiple Reaction Monitoring) scans used to define molecular species need to be known (see Note 35). As MTL complex contains a small amount of lipids, only the main lipids (PC, PE and DGDG) are detected and quantified (see Note 36). Negligible amounts of lipids are detected in control bands (Figure 3A, crt1 and crt 2) showing that the MTL complex is truly enriched in lipids [8]. The Table 1 describes the acquisition settings for the glycerolipids analyzed.

5. To quantify each molecule of lipid, each chromatographic peak is integrated by the mass spectrometer software. The area of the peak is proportional to the quantity of the molecule. Because mass spectrometry detection efficiency is always molecule dependent, the 
internal standard is used to correct molecule bias quantification. Each molecular species (ms_LIP) of a lipid class (lc_LIP) is corrected by its corresponding internal standard (lc_is) to neglect the matrix effect by applying the following formula with Q corresponding to the quantity in pmol:

$$
Q\left(m s_{-} L I P\right)=\frac{\operatorname{Area}\left(m s_{\_} L I P\right)}{\text { Area }\left(l c_{-} i s\right)} * Q\left(l c_{-} i s\right) .
$$

Then all molecules of the same lipid class are summed to obtain the quantity of one lipid class:

$$
Q\left(l_{-} L I P\right)=\sum Q\left(m s_{-} L I P\right)
$$

Data are then expressed in mol\% of PC, PE and DGDG in the MTL complex or in mitochondria membranes (Figure 3B). Typically, in Col0 callus, we observe an increase in the DGDG content and a decrease in $\mathrm{PE}$ and PC in both mitochondria membranes and MTL complex. However, in absence of AtMic60, DGDG barely increase during Pi starvation. Interestingly, whereas the level of PE slightly decreases in mitochondria membranes, it increases in the atmic60 MTL complex during Pi starvation, suggesting that PE accumulates inside the MTL complex. These results show that the traffic of both DGDG and PE is altered in atmic60 mitochondria during Pi starvation.

\section{Notes}

1. Quartz wool corresponds to pure $\mathrm{SiO}_{2}$ wool with fiber thickness from 4 to $12 \mu \mathrm{m}$. It does not react with solvent and do not contain lipids.

2. Rinse potter pestles with distilled water, then ethanol.

3. If the evaporator bath could warm: put the set temperature at $40^{\circ} \mathrm{C}$ maximum. It will decrease the evaporation time.

4. To prepare the standard solution at $0.5 \mathrm{mg} / \mathrm{mL}$ : put $25 \mathrm{mg}$ of C15 in a $1.5 \mathrm{~mL}$ tube. Add $1 \mathrm{~mL}$ of chloroform/methanol 1/2 (v/v), make hand agitation. Transfer this solution in a graduated flask of $50 \mathrm{~mL}$. Complete until $50 \mathrm{~mL}$ with chloroform/methanol 1/2 (v/v). Put a glass cap and parafilm around. Make some inversions. Put some milliliters of this $\mathrm{C} 15$ solution in a little beaker (to avoid evaporation) and realize aliquots of $500 \mu \mathrm{L}$ and store them at $-20^{\circ} \mathrm{C}$.

5. Prepare the solution at $4^{\circ} \mathrm{C}$ to avoid overheating of the solution. Put $400 \mathrm{~mL}$ of methanol in a glass bottle, under agitation. Then, add slowly $10 \mathrm{~mL}$ of sulfuric acid. Put a glass cap and store at RT.

6. All the stock standard solutions need to be quantified by GC-FID to be sure the concentrations are accurate. If necessary volume will be adjusted to be sure the standard solution will be at $1.25 \mu \mathrm{M}$ for each standard.

7. Solubilize $5 \mathrm{mg}$ of DGDG in $1 \mathrm{~mL}$ of chloroform in a glass vial HPLC type. Add a small spatula of $\mathrm{PtO}_{2}$ powder (catalyser). Add a small bar magnet $(4 \mathrm{~mm})$. Label the level of liquid on the vial. Close the vial, add at the center of the lid 2 thin needles to allow hydrogen to 
get in and out. Needles need to be above the liquid. Prepare an Erlen with a lid insensitive to chloroform with 2 holes, one for the entrance of hydrogen and the other one for a "safety valve" constituted of a Pasteur pipette with a finger of cut latex glove. Put the HPLC vial into the Erlen with the gaz entrance of the Erlen connected to the first needle of the vial (use silicon tube and junctions). Put the Erlen above a magnet stirrer under the fume hood. Open the hydrogen bottle or generator to deliver 3.5 bars maximum to fill the Erlen with hydrogen then reduce the pressure to 1 bar. Leave overnight under small stirring. The following day recover the lipid by eventually adding chloroform and collecting the liquid. Quantify and check the DGDG composition by methanolysis and GC-FID (methods 3.7.3 and 3.7.4)

8. Here, settings are described for an HPLC Agilent 1200 and a triple quadripole Agilent 6460. Parameters might vary for other instruments.

9. To avoid pipetting of seeds, centrifuge the tubes few seconds at low speed and pipette carefully the solution without touching the seeds.

10. To obtain stable culture, transfer $50 \mathrm{~mL}$ of the 7 day old culture into a sterile $50 \mathrm{~mL}$ tube. Wait until the callus sediment (the volume of callus should not exceed $5 \mathrm{~mL}$ ) and throw away the excess of media. Recover the callus by resuspending them with fresh media and transfer them into the culture flask. Complete the media to $200 \mathrm{~mL}$.

11. Materials for mitochondria preparations (tubes, glassware...) have to be free of detergent. It is recommended to dedicate a batch of material to mitochondria preparation and to wash the material with distillated water only.

12. After filtration, cells have to be maintained at $4^{\circ} \mathrm{C}$ before grinding. Thus, a pre-chilled mortar is stored on ice close to the balance. Cells are immediately deposited inside after weighting.

13. To add the $23 \%$ and $18 \%$ Percoll layers above the Percoll $40 \%$ layer, we use a peristaltic pump. The tubes containing the $5 \mathrm{~mL}$ of Percoll $40 \%$ are slightly inclined on ice and the exit tube of the pump is fixed at the top of the $32 \mathrm{~mL}$ tube. The entry tube of the pump is dived on a falcon containing $20 \mathrm{~mL}$ of Percoll $23 \%$ and the pump is turned on. Usually, we use a flow rate of $1.5 \mathrm{~mL} / \mathrm{min}$ to layer the Percoll $23 \%$ and $18 \%$ solutions. During the distribution with the pump, the solution has to slide on the surface of the tube. If a drop falls directly on the gradient, it can create perturbation of the gradient.

14. Mitochondria purified from MS -Pi are more contaminated by the plastid fraction at this step. Thus, some green material could be visible with the mitochondria at the $23 / 40 \%$ interface.

15. At this step, the mitochondria pellet is not stable. Discard the supernatant by carefully pipetting the upper part of the tube. Leave around $5 \mathrm{~mL}$ in the tube to not loose mitochondria.

16. If labelling is performed, from this step, all samples will be radioactive and all materials and wastes in the subsequent steps have to be treated in consequence in appropriate waste disposals. 
17. We usually load $20 \mu \mathrm{g}$ of membranes per lane of gel. It is possible to load a higher quantity if necessary but we recommend to do not load more than $30 \mu \mathrm{g}$ per lane to do not disturb the migration of the MTL complex.

18. For $20 \mu \mathrm{g}$ of membranes, $30 \mu \mathrm{g}$ of DDM is added. Thus, we add 3 $\mu \mathrm{L}$ of DDM $1 \%(\mathrm{w} / \mathrm{v})$ to $20 \mu \mathrm{g}$ of membrane fraction and adjust the volume to $20 \mu \mathrm{L}$ with Membrane buffer. Higher concentration of DDM can also be used but $1.5 \%$ is the reference concentration we used to analyze the MTL complex.

19. The native gel can be casted the day before the experiment and stored at $4^{\circ} \mathrm{C}$. Do not use a gel that have been stored more than $48 \mathrm{~h}$ at $4^{\circ} \mathrm{C}$.

20. At this step, it is important to go as fast as possible to avoid the polymerization of the gel in the gradient chamber or in the pump system. If more than one gel is required, it is better to cast one gel then, prepare a new mix of $12 \%$ and $3.5 \%$ separation gel and finally cast the second gel.

21. Do not vortex or heat the samples before loading in the gel.

22. Do not perform the migration at a voltage higher than $80 \mathrm{~V}$ to avoid the formation of a smear by the MTL complex.

23. The fixation can also be performed overnight.

24. This process of fixation and staining is compatible with a subsequent analysis by mass spectrometry

25. Add a thin plastic layer that do not absorb the radiation between the dried gel and the screen.

26. Mitochondria membranes can be stored at $-80^{\circ} \mathrm{C}$ if long storage is required.

27. Be careful: samples should not dry. If there is almost no liquid left, take out the tube from the bath before $5 \mathrm{~min}$ of incubation and continue the protocol. If several extractions are done in the same time, it is recommended to treat each sample one by one at this step.

28. Open the argon very slowly after putting Pasteur pipette into the liquid to avoid any spilling of the solvent.

29. To avoid any contamination with the upper phase, use a propipette on top of the Pasteur pipette. Suck a little bit of air into the pipette, plunge it at the bottom of the tube, eject one or 2 bubbles that will reject any upper phase that might have penetrate into the pipette and suck up the lower phase.

30. The bands can be stored at $-80^{\circ} \mathrm{C}$ if long storage is required.

31. Put the aliquot of standard $\mathrm{C} 15$ at least $20 \mathrm{~min}$ at room temperature before use. No overthrow but gently agitation. 
32. We have verified that the method is within a linear range up to 15 nmol of total fatty acid.

33. The distinct glycerophospholipid classes were eluted successively as a function of the polar head group. Under these conditions, they were eluted in the following order: DGDG, PE and PC.

34. For a 6460 triple quadrupole mass spectrometer (Agilent) equipped with a Jet stream electrospray ion source the source parameters are the following settings: Drying gas heater: $260^{\circ} \mathrm{C}$, Drying gas flow 13 $\mathrm{L} / \mathrm{min}$, Sheath gas heater: $300^{\circ} \mathrm{C}$, Sheath gas flow: $11 \mathrm{~L} / \mathrm{min}$, Nebulizer pressure: 25 psi, Capillary voltage: $\pm 5000 \mathrm{~V}$, Nozzle voltage \pm 1000 . Nitrogen is used as collision gas.

35. To use this method, the studied organism glycerolipidome needs to be known. Only lipid transitions that are entered in the method will be measured. It is a targeted method.

36. After an initial analysis, only three lipids (PC, DGDG and PE) were detected in the MTL complex. If all the lipids need to be analyzed, you can find all the transitions and standards we usually use in our lab in [15]. 
Table 1. Transition and mass spectrometer parameters used to detect and quantify Arabidopsis lipids. Prec Ion: precursor ion; Res: resolution; Prod Ion: product ion; DGDG: digalactosyldiacylglycerol; PE: phosphatidylethanolamine; PC: phosphatidylcholine.

\begin{tabular}{|c|c|c|c|c|c|c|c|c|c|c|}
\hline \multicolumn{11}{|c|}{ Segment 1: from 0 to $7 \mathrm{~min}$} \\
\hline $\begin{array}{c}\text { Compound } \\
\text { Group }\end{array}$ & Compound Name & Prec Ion & MS1 Res & Prod Ion & MS2 Res & Dwell & Fragmentor & $\begin{array}{c}\text { Collision } \\
\text { Energy }\end{array}$ & $\begin{array}{c}\text { Cell } \\
\text { Accelerator } \\
\text { Voltage }\end{array}$ & Polarity \\
\hline DGDG & DGDG-36-1 & 964 & Widest & 623 & Unit & 30 & 135 & 8 & 7 & Positive \\
\hline DGDG & DGDG-36-2 & 962 & Widest & 621 & Unit & 30 & 135 & 8 & 7 & Positive \\
\hline DGDG & DGDG-36-3 & 960 & Widest & 619 & Unit & 30 & 135 & 8 & 7 & Positive \\
\hline DGDG & DGDG-36-4 & 958 & Widest & 617 & Unit & 30 & 135 & 8 & 7 & Positive \\
\hline DGDG & DGDG-36-5 & 956 & Widest & 615 & Unit & 30 & 135 & 8 & 7 & Positive \\
\hline DGDG & DGDG-36-6 & 954 & Widest & 613 & Unit & 30 & 135 & 8 & 7 & Positive \\
\hline DGDG & DGDG-34-0 & 938 & Widest & 597 & Unit & 30 & 135 & 8 & 7 & Positive \\
\hline$\overline{\text { DGDG }}$ & DGDG-34-1 & 936 & Widest & 595 & Unit & 30 & 135 & 8 & 7 & Positive \\
\hline DGDG & DGDG-34-2 & 934 & Widest & 593 & Unit & 30 & 135 & 8 & 7 & Positive \\
\hline DGDG & DGDG-34-3 & 932 & Widest & 591 & Unit & 30 & 135 & 8 & 7 & Positive \\
\hline DGDG & DGDG-34-4 & 930 & Widest & 589 & Unit & 30 & 135 & 8 & 7 & Positive \\
\hline DGDG & DGDG-34-5 & 928 & Widest & 587 & Unit & 30 & 135 & 8 & 7 & Positive \\
\hline DGDG & DGDG-34-6 & 926 & Widest & 585 & Unit & 30 & 135 & 8 & 7 & Positive \\
\hline DGDG & DGDG-32-1 & 908 & Widest & 567 & Unit & 30 & 135 & 8 & 7 & Positive \\
\hline DGDG & DGDG-32-2 & 906 & Widest & 565 & Unit & 30 & 135 & 8 & 7 & Positive \\
\hline DGDG & DGDG-32-3 & 904 & Widest & 563 & Unit & 30 & 135 & 8 & 7 & Positive \\
\hline \multicolumn{11}{|c|}{ Segment 2: from 7 to 16 min } \\
\hline $\begin{array}{c}\text { Compound } \\
\text { Group }\end{array}$ & Compound Name & $\begin{array}{c}\text { Precursor } \\
\text { Ion }\end{array}$ & MS1 Res & $\begin{array}{c}\text { Product } \\
\text { Ion }\end{array}$ & MS2 Res & Dwell & Fragmentor & $\begin{array}{c}\text { Collision } \\
\text { Energy }\end{array}$ & $\begin{array}{c}\text { Cell } \\
\text { Accelerator } \\
\text { Voltage }\end{array}$ & Polarity \\
\hline DGDG & DGDG-36-0 & 966 & Widest & 625 & Unit & 30 & 135 & 8 & 7 & Positive \\
\hline DGDG & DGDG-36-1 & 964 & Widest & 623 & Unit & 30 & 135 & 8 & 7 & Positive \\
\hline DGDG & DGDG-36-2 & 962 & Widest & 621 & Unit & 30 & 135 & 8 & 7 & Positive \\
\hline DGDG & DGDG-36-3 & 960 & Widest & 619 & Unit & 30 & 135 & 8 & 7 & Positive \\
\hline DGDG & DGDG-36-4 & 958 & Widest & 617 & Unit & 30 & 135 & 8 & 7 & Positive \\
\hline DGDG & DGDG-36-5 & 956 & Widest & 615 & Unit & 30 & 135 & 8 & 7 & Positive \\
\hline DGDG & DGDG-36-6 & 954 & Widest & 613 & Unit & 30 & 135 & 8 & 7 & Positive \\
\hline DGDG & DGDG-34-0 & 938 & Widest & 597 & Unit & 30 & 135 & 8 & 7 & Positive \\
\hline DGDG & DGDG-34-1 & 936 & Widest & 595 & Unit & 30 & 135 & 8 & 7 & Positive \\
\hline DGDG & DGDG-34-2 & 934 & Widest & 593 & Unit & 30 & 135 & 8 & 7 & Positive \\
\hline DGDG & DGDG-34-3 & 932 & Widest & 591 & Unit & 30 & 135 & 8 & 7 & Positive \\
\hline DGDG & DGDG-34-4 & 930 & Widest & 589 & Unit & 30 & 135 & 8 & 7 & Positive \\
\hline DGDG & DGDG-34-5 & 928 & Widest & 587 & Unit & 30 & 135 & 8 & 7 & Positive \\
\hline DGDG & DGDG-34-6 & 926 & Widest & 585 & Unit & 30 & 135 & 8 & 7 & Positive \\
\hline DGDG & DGDG-32-1 & 908 & Widest & 567 & Unit & 30 & 135 & 8 & 7 & Positive \\
\hline DGDG & DGDG-32-2 & 906 & Widest & 565 & Unit & 30 & 135 & 8 & 7 & Positive \\
\hline DGDG & DGDG-32-3 & 904 & Widest & 563 & Unit & 30 & 135 & 8 & 7 & Positive \\
\hline Std DGDG & DGDG-32-0 & 910 & Widest & 569 & Unit & 30 & 135 & 8 & 7 & Positive \\
\hline $\mathrm{PE}$ & PE-36-1 & 746 & Widest & 605 & Unit & 30 & 135 & 20 & 7 & Positive \\
\hline $\mathrm{PE}$ & PE-36-2 & 744 & Widest & 603 & Unit & 30 & 135 & 20 & 7 & Positive \\
\hline $\mathrm{PE}$ & PE-36-3 & 742 & Widest & 601 & Unit & 30 & 135 & 20 & 7 & Positive \\
\hline $\mathrm{PE}$ & PE-36-4 & 740 & Widest & 599 & Unit & 30 & 135 & 20 & 7 & Positive \\
\hline $\mathrm{PE}$ & PE-36-5 & 738 & Widest & 597 & Unit & 30 & 135 & 20 & 7 & Positive \\
\hline$\overline{\mathrm{PE}}$ & PE-36-6 & 736 & Widest & 595 & Unit & 30 & 135 & 20 & 7 & Positive \\
\hline $\mathrm{PE}$ & PE-34-1 & 718 & Widest & 577 & Unit & 30 & 135 & 20 & 7 & Positive \\
\hline $\mathrm{PE}$ & PE-34-2 & 716 & Widest & 575 & Unit & 30 & 135 & 20 & 7 & Positive \\
\hline $\mathrm{PE}$ & PE-34-3 & 714 & Widest & 573 & Unit & 30 & 135 & 20 & 7 & Positive \\
\hline $\mathrm{PE}$ & PE-34-4 & 712 & Widest & 571 & Unit & 30 & 135 & 20 & 7 & Positive \\
\hline $\mathrm{PE}$ & PE-32-1 & 690 & Widest & 549 & Unit & 30 & 135 & 20 & 7 & Positive \\
\hline $\mathrm{PE}$ & PE-32-2 & 688 & Widest & 547 & Unit & 30 & 135 & 20 & 7 & Positive \\
\hline std PE & PE-36-0 & 748 & Widest & 607 & Unit & 30 & 135 & 20 & 7 & Positive \\
\hline \multicolumn{11}{|c|}{ Segment 3: from 16 to $40 \mathrm{~min}$} \\
\hline $\begin{array}{l}\text { Compound } \\
\text { Group }\end{array}$ & Compound Name & $\begin{array}{c}\text { Precursor } \\
\text { Ion }\end{array}$ & MS1 Res & $\begin{array}{c}\text { Product } \\
\text { Ion }\end{array}$ & MS2 Res & Dwell & Fragmentor & $\begin{array}{c}\text { Collision } \\
\text { Energy }\end{array}$ & $\begin{array}{c}\text { Cell } \\
\text { Accelerator } \\
\text { Voltage }\end{array}$ & Polarity \\
\hline
\end{tabular}




\begin{tabular}{|l|l|l|l|l|l|l|l|l|l|l|}
\hline PC & PC-36-1 & 788 & Widest & 184 & Unit & 30 & 135 & 34 & 7 & Positive \\
\hline PC & PC-36-2 & 786 & Widest & 184 & Unit & 30 & 135 & 34 & 7 & Positive \\
\hline PC & PC-36-3 & 784 & Widest & 184 & Unit & 30 & 135 & 34 & 7 & Positive \\
\hline PC & PC-36-4 & 782 & Widest & 184 & Unit & 30 & 135 & 34 & 7 & Positive \\
\hline PC & PC-36-5 & 780 & Widest & 184 & Unit & 30 & 135 & 34 & 7 & Positive \\
\hline PC & PC-36-6 & 778 & Widest & 184 & Unit & 30 & 135 & 34 & 7 & Positive \\
\hline PC & PC-34-0 & 762 & Widest & 184 & Unit & 30 & 135 & 34 & 7 & Positive \\
\hline PC & PC-34-1 & 760 & Widest & 184 & Unit & 30 & 135 & 34 & 7 & Positive \\
\hline PC & PC-34-2 & 758 & Widest & 184 & Unit & 30 & 135 & 34 & 7 & Positive \\
\hline PC & PC-34-3 & 756 & Widest & 184 & Unit & 30 & 135 & 34 & 7 & Positive \\
\hline PC & PC-34-4 & 754 & Widest & 184 & Unit & 30 & 135 & 34 & 7 & Positive \\
\hline PC & PC-32-0 & 734 & Widest & 184 & Unit & 30 & 135 & 34 & 7 & Positive \\
\hline PC & PC-32-1 & 732 & Widest & 184 & Unit & 30 & 135 & 34 & 7 & Positive \\
\hline PC & PC-32-2 & 730 & Widest & 184 & Unit & 30 & 135 & 34 & 7 & Positive \\
\hline Std PC & PC-36-0 & 790 & Widest & 184 & Unit & 30 & 135 & 34 & 7 & Positive \\
\hline
\end{tabular}


Figure 1: Overview of the methods used to analyse defects in lipid trafficking in the MTL complex of atmic60 mutant callus. The dashed boxes indicate the two strategies used: 1) study of the in vitro synthesis and transfer of radiolabelled galactoglycerolipids in the MTL complex; 2) study of the mitochondria membranes and MTL complex lipidome. DGDG: digalactosyldiacylglycerol, DGD: DGDG synthase, MGDG: monogalactosyldiacylglycerol, OE: outer envelope of plastids, Pi, phosphate, UDP-Gal*: UDP- $\left[{ }^{14} \mathrm{C}\right]$-galactose.

Figure 2: In vitro synthesis and transfer of radiolabelled galactoglycerolipids in the MTL complex of Col0 and atmic60 callus grown in presence (+) or absence (-) of phosphate (Pi). After labelling, the MTL complex have been isolated by CN-PAGE. A coomassie staining of the CN-PAGE and its exposure to a phosphorimager plate are shown. The MTL complex is labelled by an asterisk. C: Col0, m: atmic60, MW: molecular weight (in KDa).

Figure 3: Lipidomic analysis by mass spectrometry of the mitochondria membranes and MTL complex of Col0 and atmic60 callus grown in presence (+) or absence (-) of phosphate (Pi). A. CNPAGE bands analysed by mass spectrometry. The MTL complex and two others complexes located at different parts of the gel were analysed (crt 1 and crt 2). A control corresponding to a band cut in a lane without proteins was also included. B. Lipid content of mitochondria membranes and MTL complex of callus grown in + or $-\mathrm{Pi}$. No lipids were detected in the control bands. Only DGDG, PC and PE were detected in the MTL complex. Consequently, only these three lipids have been analysed in mitochondria membranes. The results are expressed in mol\%. DGDG: digalactosyldiacylglycerol; PE: phosphatidylethanolamine; PC: phosphatidylcholine, C: Col0, m: atmic60, MW: molecular weight (in KDa). Statistical significance of the data was evaluated with two-tailed unpaired t-test using GraphPad software. *p $<0.05, * * \mathrm{p}<0.01, \mathrm{n}=3$. 


\section{References}

1. Dacks, J.B., and Field, M.C. (2007). Evolution of the eukaryotic membrane-trafficking system: origin, tempo and mode. J Cell Sci 120, 2977-2985.

2. Nebenführ, A. (2002). Vesicle traffic in the endomembrane system: a tale of COPs, Rabs and SNAREs. Current Opinion in Plant Biology 5, 507-512.

3. Prinz, W.A. (2010). Lipid Trafficking sans Vesicles: Where, Why, How? Cell 143, 870-874.

4. Raychaudhuri, S., and Prinz, W.A. (2008). Nonvesicular phospholipid transfer between peroxisomes and the endoplasmic reticulum. Proceedings of the National Academy of Sciences $105,15785-15790$.

5. Schulz, T.A., Choi, M.G., Raychaudhuri, S., Mears, J.A., Ghirlando, R., Hinshaw, J.E., and Prinz, W.A. (2009). Lipid-regulated sterol transfer between closely apposed membranes by oxysterol-binding protein homologues. The Journal of cell biology 187, 889-903.

6. Jouhet, J., Marechal, E., Baldan, B., Bligny, R., Joyard, J., and Block, M.A. (2004). Phosphate deprivation induces transfer of DGDG galactolipid from chloroplast to mitochondria. The Journal of cell biology 167, 863-874.

7. Jouhet, J., Marechal, E., Bligny, R., Joyard, J., and Block, M.A. (2003). Transient increase of phosphatidylcholine in plant cells in response to phosphate deprivation. Febs Letters 544, 6368.

8. Michaud, M., Gros, V., Tardif, M., Brugiere, S., Ferro, M., Prinz, W.A., Toulmay, A., Mathur, J., Wozny, M., Falconet, D., et al. (2016). AtMic60 Is Involved in Plant Mitochondria Lipid Trafficking and Is Part of a Large Complex. Curr Biol 26, 627-639.

9. Boudière, L., Michaud, M., Petroutsos, D., Rébeillé, F., Falconet, D., Bastien, O., Roy, S., Finazzi, G., Rolland, N., Jouhet, J., et al. (2014). Glycerolipids in photosynthesis: Composition, synthesis and trafficking. Biochimica et Biophysica Acta (BBA) - Bioenergetics 1837, 470-480.

10. Michaud, M., Prinz, W.A., and Jouhet, J. (2017). Glycerolipid synthesis and lipid trafficking in plant mitochondria. FEBS J 284, 376-390.

11. Alonso, J.M., Stepanova, A.N., Leisse, T.J., Kim, C.J., Chen, H., Shinn, P., Stevenson, D.K., Zimmerman, J., Barajas, P., Cheuk, R., et al. (2003). Genome-wide insertional mutagenesis of Arabidopsis thaliana. Science 301, 653-657.

12. Amara, S., Barouh, N., Lecomte, J., Lafont, D., Robert, S., Villeneuve, P., De Caro, A., and Carriere, F. (2010). Lipolysis of natural long chain and synthetic medium chain galactolipids by pancreatic lipase-related protein 2. Biochimica et biophysica acta 1801, 508-516.

13. Bradford, M.M. (1976). A rapid and sensitive method for the quantitation of microgram quantities of protein utilizing the principle of protein-dye binding. Analytical biochemistry 72 , 248-254.

14. Bligh, E.G., and Dyer, W.J. (1959). A rapid method of total lipid extraction and purification. Can J Biochem Physiol 37, 911-917.

15. Jouhet, J., Lupette, J., Clerc, O., Magneschi, L., Bedhomme, M., Collin, S., Roy, S., Marechal, E., and Rebeille, F. (2017). LC-MS/MS versus TLC plus GC methods: Consistency of glycerolipid and fatty acid profiles in microalgae and higher plant cells and effect of a nitrogen starvation. PLoS One 12, e0182423. 